\title{
A Primitive Pleomorphic Adenoma of Para Pharyngeal Space:
}

\author{
Imane Azzam*, Kawtar Ayyad, Sophia Nitassi, Abdelilah Oujilal, Leila Essakalli
}

ENT Department University Hospital Rabat, Morocco

DOI: $10.36347 /$ sasjs.2020.v06i01.007

| Received: 11.01.2020 | Accepted: 18.01.2020 | Published: 29.01.2020

*Corresponding author: Azzam Imane

Abstract

Review Article

Tumors of the para-pharyngeal space are rare, accounting for $0.5 \%$ of all head tumors and neck, often benignes 70 to $80 \%$. Pleomorphic adenoma is the most common histological type. Clinical symptomatology is often poor, correlated with the mass effect of tumour on adjacent structures. We report the case of a primitive pleomorphic adenoma of the parapharyngeal space operated by cervical approch and we expose through a review of the literature on clinical characteristics, diagnostic and managment means.

Keywords: Parapharyngeal tumors, salivary glands, pleomorphic adenoma, surgery.

Copyright @ 2020: This is an open-access article distributed under the terms of the Creative Commons Attribution license which permits unrestricted use, distribution, and reproduction in any medium for non-commercial use (NonCommercial, or CC-BY-NC) provided the original author and source are credited.

\section{INTRODUCTION}

Tumors located in the parapharyngeal space are rare. They account for $0.5 \%$ of the hole tumors of the Head and neck [1,2]. The pleomorphic adenoma is the mostcommon histological type [3,4]. Clinical symptomatology is often poor, correlated with the mass effect exerted by the tumor on adjacent structures $[5,6]$.

We report the case of a primitive pleomorphic adenoma of para pharyngeal space and we will expose through a review of the literature the clinical characteristics, diagnostic means and management methods

\section{OBSERVATION}

A 38-years-old woman with no significant medical history consulted for a pharyngeal discomfort that has been evolving for 2 years, associated with nocturnal snoring, without dyspnea or dysphagia and with general state preservation.Physical examination objectified a palate bulging on the left side with forward, a tonsillary displacement to the midline as well as left laterocervical tumefaction with a diameter of $4 \mathrm{~cm}$. The rest of the ENT and somatic examination was without abnormalities.

Nasal endoscopy: showed a regular bulging of the left posterolateral wall of the cavum CT SCAN: Lesional process of mucous pharyngeal, masticatory, parapharyngeal and submandibular left space, lysing partly the homolateral pterygoid process.

MRI: Left retro and lateropharyngeal tumoral process, as well as at the homolateral prestylien space, showed a hypointense signal on $\mathrm{T} 1$ images and a hyperintense signal on T2 images, enhaced after contrast materiel administration, and showed a fatty layer between the tumor and the deep lobe of the parotid.

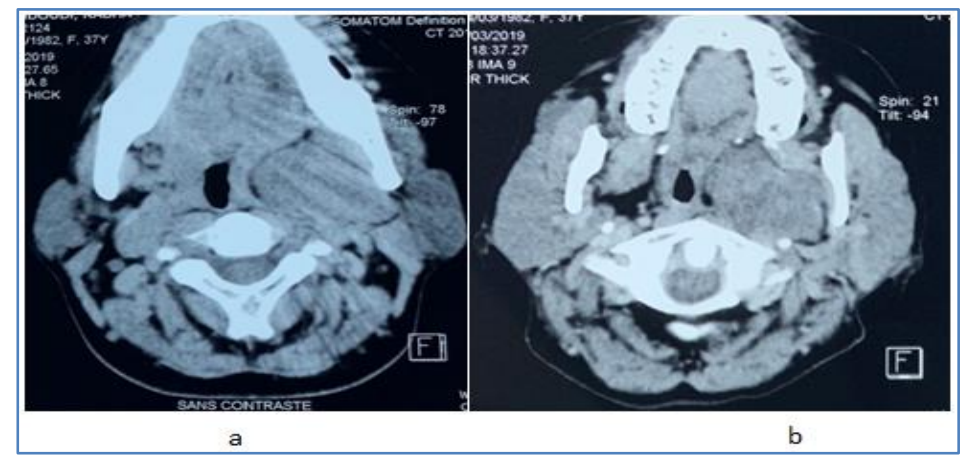

Fig-1: Axial cervical CT scan images without (a) and with (b) contrast injection showing the prestylien tumoral process 


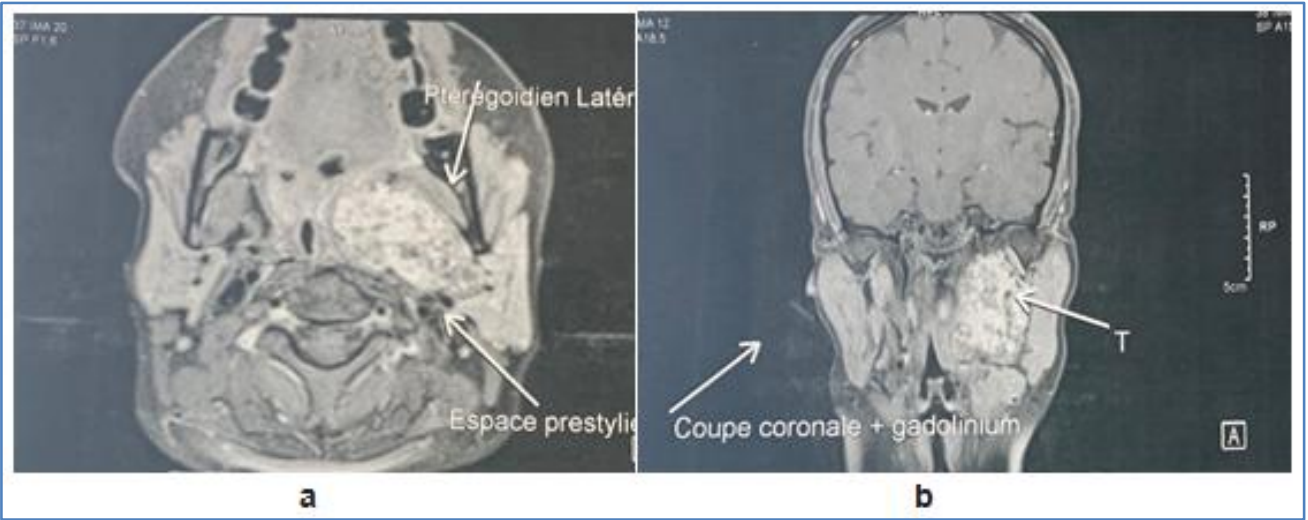

Fig-2: Axial (a) and coronal (b) gadolinium -enhanced MR images of a prestylien tumoral process

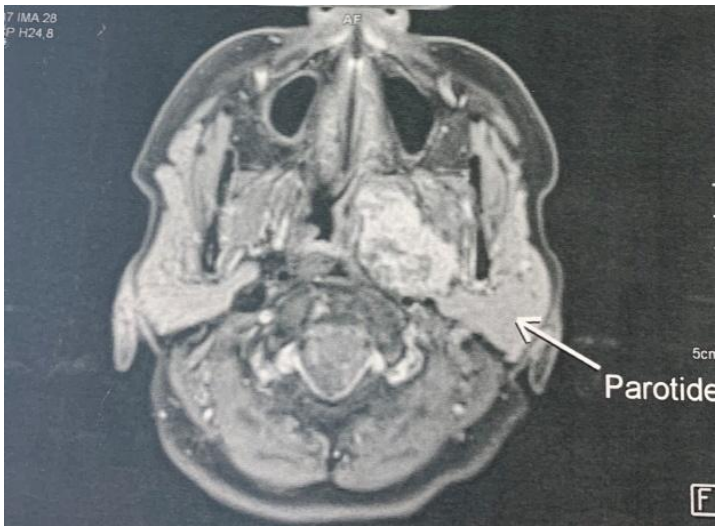

Fig-3: Axial gadolinium-enhanced MR image showing the fatty layer between the tumor and the deep lobe of the parotid gland.

The patient underwent a surgery and total excision of the lesion was performed via a cervical approach. The histological exam revealed a pleomorphic adenoma. No postoperative complications were noted and no recurrence was noted during 10months of follow-up.

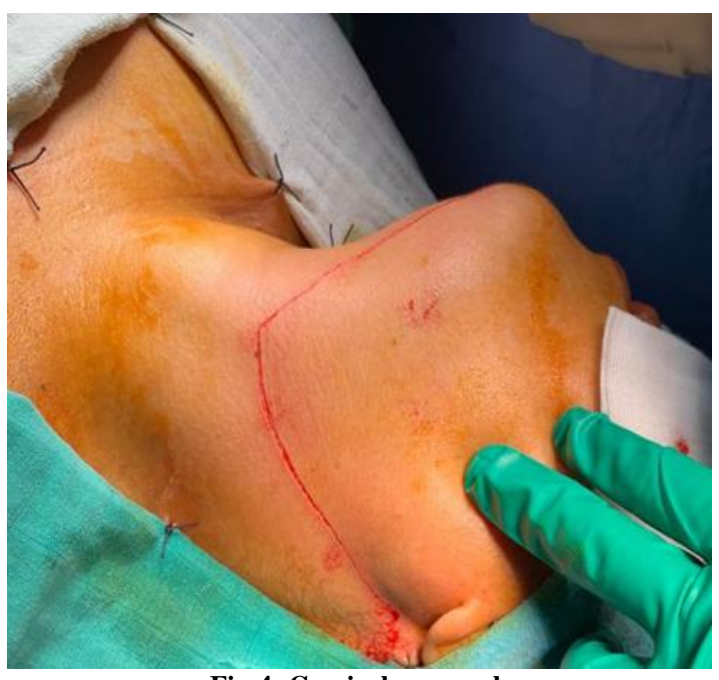

Fig-4: Cervical approach

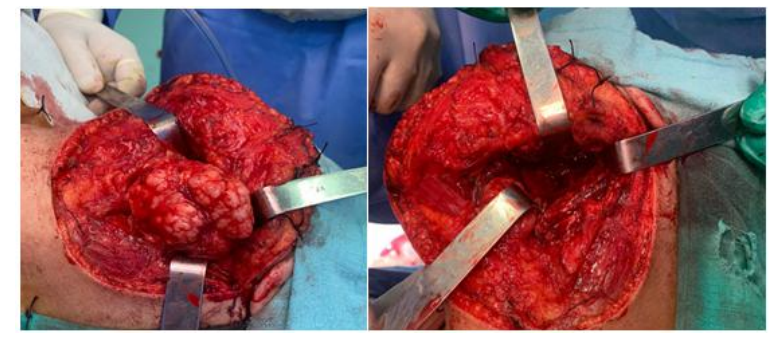

Fig-5: Peroperative images

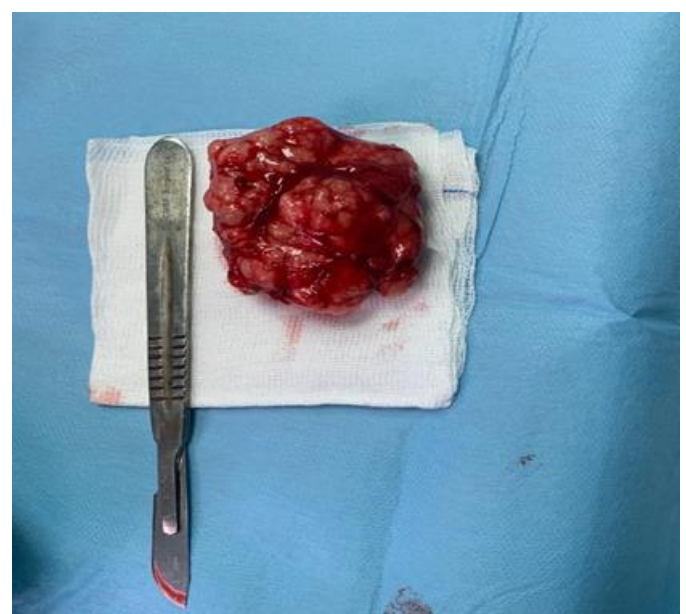

Fig-6: The excised specimen

\section{DISCUSSION}

The parapharyngeal space is a deep cervical area that has morphology of an inverted triangular pyramid extending from the base of the skull to the hyoid bone. It's subdivided by a styloid diaphragm originating at the styloid process into 2 compartments: prestyloid and retrostyloid. The prestyloid compartment is occupied by the mid face part of the parotid gland, fat tissue and nerves. In the retrostyloid compartment sit vascular, neural and paraganglionic structures.

Parapharyngeal space tumors are uncommon (0,5 within the head and neck tumors) and mostly benign [7]. Due to the diversity of the structures included in this area, varieted of tumors are described there [6]. Neural tumors (shwannoma, neurofibroma) are the most common histological types found in the retrostylien compartment [4]. While the salivary gland 
tumors are the ones most dominated in the prestylien compartment, either developed in the deep lobe of the parotid gland or an accessory salivary gland in ectopic position. Pleomorphic adenoma is the most frequent histological type [3-6]. The parapharyngeal tumors remain asymptomatic until they reach an important size, due to their development in a deep area [8]. The mean age occurrence of these tumors is around 47 years old with a female predominance [9]. The mid delay of consulting is about 9 months [10]. Our patient was 38 years old with 1 year delay consultation. The most common reasons for consultation are oropharyngeal discomfort or at deglutition, an impression of foreign body or even a dysphagia. The most frequent findings in the physical examination are a cervical or an oropharyngeal mass, or a tonsillary displacement to the midline $[9,11,12]$, which was the case of our patient who consulted for a painful left laterocervical mass with a left tonsillar discharge.

It is essential to carry out complementary radiological studies, fundamentally CT scan and MRI imaging, to confirm the diagnosis and for planning surgical approach [13]. The CT scan (axial and coronal images) allows the diagnosis of the masse, the study of its connection with the base of the skull, its vascularization and its pre or retrostylien position [14].The tumor connection with the parotid gland is better characterized by the MRI exam that also refers to the most probable histological diagnosis $[14,15]$. It also enables to distinguish masses in the deep lobe of the parotid from an extra parotid tumor of the minor salivary glands that is extending into the parapharyngeal space, from evidence of the flatty layer between the tumor and the parapharyngeal wall $[11,16]$. For the pleomorphic adenoma the MRI shows a hypointense signal on $\mathrm{T} 1$ images and a hyperintense signal on T2 images [17]. In our case, the MRI shows a lesional process at the left prestylien compartment, with similar characteristics. Angiography study is indicated in tumors for which the CT scan suggested a neurogenic or vascular origin [14]. Arteriography is used in highly vascularized tumors and those requiring embolization before surgery, which should be performed in these cases 1-3 days before the operation [9]. In our case, the angiography performed eliminated the vascular origin.

The FNA represents another diagnosis device. It can be performed by a transoral or percutaneous route guided by CT or ultrasound scan [18]. It wasn't performed for our patient. Biopsy performed either by transoral or cervical route is contraindicated because of the risk of tumoral effraction and recurrence [1].

The treatment of these tumors is surgical. The surgical approach determines the success of the surgical procedure. The surgical goal should be to remove the lesion intact without rupture, and with lower risk of vessels or nerves injury [19, 20].
Several approaches have been described for complete removal of these tumors: simple (cervical, cervical-transparotid and transoral), or combined: cervical and transoral, transmandibular, transpharyngeal. The choice depends on tumor location, the relationship between the tumor, the large blood vessels and the nerves, and the surgeon experience. The main surgical approach is the cervical transparotid approach [18]. It provides an adequate exposure of the neurovascular structures. The transoral approach had been reported to be effective for removing selected benign minor salivary tumors that have extended into the parapharyngeal space [21]. However, it provides poor exposure, a lake of wide access to regional vessels and nerves, and a high risk of spillage with possible recurrence [22, 23]. For our case, the cervical approach had been used like it's described in the literature [24, 25].

For our patient, an integral resection of the tumor was performed. The postoperative course was simple. The final histological result was a pleomorphic adenoma. There have been no recurrences in our case after 10 months post intervention. The rate of recurrence described in the literature varied from 0 to 17 percent, with a recurrence time of 35 months [14]. This can be due to the spilling of the tumor when the resection [4].

\section{CONCLUSION}

Parapharyngeal tumors are varied because of the diversity of the anatomic structures in this area. Clinical symptomatology still poor which make the diagnosis difficult and delayed. Complementary imaging studies (CT scan and MRI) are essential both of diagnosis and for planning treatment approach. Treatment is always surgical. The surgical approach determines the success of the surgical procedure, which depends on the radiological evaluation.

\section{REFERENCES}

1. Sergi B, Limongelli A, Scarano E, Fetoni AR, Paludetti G. Giant deep lobe parotid gland pleomorphic adenoma involving the parapharyngeal space.Report of three cases and review of the diagnostic and therapeutic approaches. Acta otorhinolaryngol ital. 2008; 28: 261-5.

2. Hakeem Ah, Hazarika B, Pradhan SA, Kannan R. Primary pleomorphic adenoma of minor salivary gland in the parapharyngeal space. World J Surg oncol.2009; 7: 85

3. Bozza F, Vigili MG, Ruscito P, marzetti A, marzetti F. Surgical management of parapharyngeal space tumours: results of 10-year follow-up. Actaotorhinolaryngol ital. 2009; 29: 10.

4. Pang KP, Goh Ch, Tan HM. Parapharyngeal space tumours: An 18 year review. J Laryngol otol. 2002; 116: 170. 
5. Morita N, Miyata K, Sakamoto T, Wada $\mathrm{T}$. Pleomorphic adenoma in the parapharyngeal space. J oral maxillofac Surg. 1995; 53: 605- 610.

6. Varghese BT, Sebastian P, Abraham eK, mathews A. A case Report: Pleomorphic adenoma of minor salivary gland in the parapharyngeal space. World J Surg oncol. 2003, 1:2

7. Batsakis JG, Sneige N. Parapharyngeal and retropharyngeal space diseases. Ann Otol Rhinol Laryngol. 1989;98:320-1.

8. Keane WM. Tumors of the parapharyngeal space. In: Gates G, editor. Current therapy in otolaryngology-head and neck surgery. Philadelphia: WB Saunders. 1998: 242-6.

9. Gianluigi G, Vanessa S, Maria Gabriella M, Maria C, José Luis F. Acta otorrinolaringol esp. 2017 68(3): 138-144.

10. Ruiz-Laza L, hernandez-Guisado JM, GutierrezPerez JL. Giant pleomorphic adenoma in the parapharyngeal space: report of 2 cases. $\mathrm{J}$ oral maxillofac Surg. 2006; 64: 519-23.

11. Sergi B, Limongelli A, Scarano E, Fetoni AR, Paludetti G. Giant deep lobe parotid gland pleomorphic adenoma involving the parapharyngeal space. Report of three cases and review of the diagnostic and therapeutic approaches. Acta Otorhinolaryngologica Italica. 2008 Oct;28(5):261.

12. Haoliang C, MDS, Guowen S, DDS, MD,PDH, Enyi T, MDS, Quingang H, DDS, MD, PHD. Journal of oral and maxillofacial surgery.

13. Carrau RL, Myers EN, Jonhson JT. Management of tumoursarising in the parapharyngeal space. Laryngoscope.1990; 100:583---9.

14. Miller FR. Magnetic resonance imaging and the management of parapharyngeal space tumors. Head Neck. 1996; 18:67-77.
15. Leverstein H, Castelijns JA, Snow GB. The value of magnetic resonance imaging in the differential diagnosis of parapharyngeal space tumours. Clin Otolaryngol. 1995; 20:428-33.

16. Shin JH. Imaging of parapharyngeal space lesions: focus on the prestyloid compartment. AJR Am J Roentgenol. 2001; 177:1465-70.

17. Makeieff M, Guerrier B. Les tumeurs parapharyngées. EMC - Oto-rhino-laryngologie 1.Volume 20-605-C-10 2012.

18. Ruiz-Laza L. Hernandez-Guisado JM, GutierrezPerez JL. Giant pleomorphic adenoma in the parapharyngeal space: report of 2 cases. $\mathbf{J}$ oral maxillofac Surg. 2006; 64: 519-23.

19. Carrau RL, Myers EN, Johnson JT. Management of tumors arising in the parapharyngeal space. Laryngoscope. 1990; 100, 6: 583-9.

20. Pang KP, Goh Ch, Tan HM. Parapharyngeal space tumours: An 18 year review. Laryngol otol. 2002; 116: 170.

21. Goodwin WJ, Chandler JR. Transoral excision of lateral parapharyngeal space tumors presenting intraorally. Laryngoscope. 1988; 98:266-9.

22. Allison RS, Van der Waal I, Snow GB. Parapharyngeal tumors: a review of 23 cases. Clin Otolaryngol. 1989;14:199-203.

23. Ducic Y, Oxford L, Pontius AT. Transoral approach to the superomedial parapharyngeal space. Otolaryngol Head Neck Surg. 2006;134:466-70.

24. Kanzaki S. Standardised method of selecting surgical approaches to benign parapharyngeal space tumours, based on pre-operative images.J Laryngol Otol. 2008;122:628-34.

25. Bass RM. Approaches to the diagnosis and treatment of tumors of the parapharyngeal space. Head Neck Surg. 1982;4:281-9. 